\title{
EFFECT OF EIGHT WEEKS OF WRESTLING AND CIRCUIT FITNESS TRAINING ON APO LIPOPROTEIN A-I AND LYMPHOCYTE ABCA1 GENE EXPRESSION IN WELL-TRAINED WRESTLERS
}

\author{
Amir Rashidlamir, Arash Saadatnia, Ahmad Ebrahimi-Atri, Mahmoud Delphan \\ Faculty of Physical Education and Sport Sciences, Ferdowsi University of Mashhad, Mashhad, Iran \\ amir.rashidlamir@gmail.com
}

\begin{abstract}
:
Introduction: Atherosclerotic cardiovascular disease is now the leading cause of death in most countries. The ABCA1 gene provides instructions for the production of proteins (ATP-binding transporter protein) whose function is to export phospholipid and cholesterol out of the cells where they are bound to circulating apolipoprotein $A 1$ (apoA1) and removed in the liver. Increased ABCA1 activity could inhibit atherosclerosis. In the present study, ABCA1 gene expression in lymphocytes and the associated effect of exercise were studied. Method: Subjects were 16 well-trained wrestlers randomly assigned into experimental and control groups. The experimental group performed 8 weeks of wrestling and circuit fitness training and the control group remained sedentary. Blood samples were collected 48 hours before the first session and 48 hours after the last session (subjects were fasting). After isolating lymphocytes by centrifugation, ABCA1 gene expression in lymphocytes was measured using semi-quantitative-RT-PCR. Data analyzed by SPSS software (version 16). Results: a significant increase in lymphocyte ABCA1 gene expression was shown following the 8 weeks of training (experimental $p<0.001, t=-$ 9.954). Plasma HDL-C concentrations and $A p o A-I$ increased $(P<0.001, t=4.97 P<0.05, t=2.67$ respectively) and plasma LDL-C concentration decreased $(P<0.001, t=4.35)$ in experimental group when compared with the control group. Discussion and Conclusion: Anaerobic exercises like wrestling and circuit fitness training can increase ABCA1 gene expression, an effective factor in the prevention of cardiovascular disease.
\end{abstract}

KEYWORDS: ABCA1, lymphocyte, circuit training

\section{INTRODUCTION:}

Coronary artery disease is now the leading cause of death worldwide. An early sign of atherosclerosis is the accumulation of cholesterol-loaded macrophages (foam cells) in the intima of arteries. An elevated plasma level of low-density lipoproteins (LDL) is a risk factor for atherosclerosis, mainly because this lipoproteins deposit cholesterol within cells of the arterial wall. Numerous epidemiological studies have also demonstrated that plasma levels of high-density lipoproteins (HDL), and their major protein constituent apolipoprotein A-I (apoA-I) are inversely correlated with the risk of atherosclerosis [1].Moreover, rising HDL cholesterol inhibits atherogenesis in several genetic animal models [2].

This protective effect of HDL-C against atherosclerosis $[3,4]$ is due to the HDL-C role in Reverse cholesterol transport (RCT). In RCT, HDL-C mediates the removal of excess free cholesterol from peripheral cells to the liver for excretion as bile [5]. In RCT process, the formation and remodeling of HDL-C in plasma require several factors such as ATP-binding cassette transporters, particularly ABCA1 that its action is a key element of the reverse cholesterol transport pathway $[6,7,8,9]$.

ABCA1 is a protein expressed abundantly in liver, macrophages brain and various other tissues [10,11] and facilitates delivery of phospholipids from cell membranes to lipid-poor ApoA-1 with the formation of ApoA-I containing HDL and it is play a pivotal role in plasma HDL formation [10,12,13,14,15]. ABCA1 is essential for the maintenance of plasma HDL-cholesterol levels. It is generally accepted that an increase in liver ABCA1 expression will has a heavily impact on plasma HDL-C formation and protects against atherosclerosis [16,17,18]. ABCA1 is responsible for lipidation of lipid-poor apolipoprotein A-I (ApoA-I) by cellular cholesterol and phospholipid, a rate-limiting step in both high density lipoprotein formation and cholesterol efflux [19,20]. Environmental factors likely contribute significantly to variation in ABCA1 expression and plasma HDL-C in the general population [21,22]. Therefore, in this study, measured ABCA1 expression in human lymphocytes, may partially reflect that in macrophages. 


\section{MATERIAL AND METHODS:}

Study participants: The subjects were 16 well-trained wrestlers randomly assigned into experimental and control groups. The experimental group performed wrestling and circuit physical fitness training six sessions per week for 8 weeks, and the control group remained sedentary.

Study design: Weight was measured to the nearest $0.1 \mathrm{~kg}$ on a digital scale both before and at the end of the research program. Heart rates were monitored during the research program by heart rate monitors device (Polar ${ }^{\circledR}$ model F1). Subjects exercised with an average of $85-90 \%$ HR max. Body fat percentages were obtained using skinfoild caliper measures from three sites (22). Participants presented to the laboratory 48 hours before the first training session and 48 hours after the last session at $8 \mathrm{am}$. This followed an overnight fast and rest without exercise. A $10 \mathrm{cc}$ fasting venous blood sample taken from the brachial vein was obtained. Blood samples were collected in test tubes anticoagulated with EDTA. Peripheral blood mononuclear cells were isolated by lymphocyte density gradient centrifugation (Cedarlane, Laboratories Limited, Burlington, Canada) at $900 \mathrm{~g}$, according to the manufacturer's instructions and the pellet containing the lymphocytes was used for further analyses.

ABCA1 expression and abundance: The lymphocyte was powdered with cold mortar and pestle, and approximately $50 \mathrm{mg}$ was used for the isolation of RNA. Total RNA was extracted by the guanidine thiocyanate method [25] and mRNA purified using an mRNA Isolation Kit (Roche, Germany) according to the manufacturer's instructions. Two-hundred nanograms of mRNA was used for synthesis of first strand cDNA by using oligo (dT) primer in the first-strand synthesis kit (Fermentase, Germany). Relative expression levels of ABCA1 mRNA in the lymphocyte were determined using a semi-quantitative PCR method. The following primers were used to amplify rat ABCA1 and b-actin (as an internal control) CDNA: ABCA1-Forward: 50-CGT CCT CCT TGT CAT CTC TG-30. ABCA1-Reverse: 50-TAA CTT TCT TTC ACT TTC TCG TC-30. b-actin- Forward: 50-TCC TGT GGC ATC CAT GAA ACT-30; b-actin-Reverse: 50-ATC GTG CAC CGC AAA TGC TTC-30. ABCA1 CDNA was amplified yielding a 237-bp product. PCR was formed for 35 cycle of denaturation $94^{\circ} \mathrm{C}$ for $30 \mathrm{~s}$, annealing of $55.5^{\circ} \mathrm{C}$ for $30 \mathrm{~s}$ and extension at $72 \mathrm{C}$ for $50 \mathrm{~s}$. Reactions were set up u sing a twofold serial dilution of template cDNA to assess the best dilution of template in PCR. Template cDNA was standardized by amplification of a 315-bp internal control of b-actin, a house keeping gene. All the reactions were repeated a minimum of three times to ensure repeatability. All PCR products were electrophoresed on an agarose gel and bands visualized by ethidium bromide staining and quantitated by computer integrated densiometry (Kodak, CT). Levels of mRNA were expressed as a ratio of signal intensity for the b-actin gene.

Lipoproteins and apolipoprotein A-I: Plasma high-density lipoprotein cholesterol (HDL) was determined by direct immuno method (HDL-C Immuno FS, Pars Azmoun, Tehran, Iran), the intra-assay coefficient of variation and sensitivity of the method were $1.2 \%$ and $0.03 \mathrm{mmol} / \mathrm{L}$. The procedure of Friedewald was used to estimate low-density lipoprotein cholesterol (LDL-C). Apolipoprotein A1 was determined by ELISA method (Wuham USCN Sciences Co. LTD, Wuhan, China).

\section{STATISTICS}

All results are expressed as means $\pm S D$. All variables were compared by unpaired t-tests. Correlations wwere calculated using the Pearson Product Moment correlation. All statistical analysis was performed by using SPSS (Version 16).

\section{RESULTS}

Participant characteristics: The average age of the participants was $17.44 \pm 0.92$ (mean $\pm S D$.) years for control group and $17.33 \pm 1.05$ for experimental group, BMI was $21.06 \pm 3.11 \mathrm{~kg} / \mathrm{m}^{2}$ for control group and $22.30 \pm 4.21$ for experimental group, body fat percentage was $14.28 \pm 4.15$ for control group and $15.87 \pm 5.02$ for experimental group. Other lipid-related parameters are shown in table1

Table1. Participant characteristics

\begin{tabular}{|l|c|c|c|}
\hline Parameter & control & experimental & P value \\
\hline Age $(\mathrm{year})$ & $17.44 \pm 0.92$ & $17.33 \pm 1.05$ & $\mathrm{P}<0.81$ \\
\hline BMI(kg/m2) & $21.06 \pm 3.11$ & $22.30 \pm 4.21$ & $\mathrm{P}<0.66$ \\
\hline Body fat percentage & $14.28 \pm 4.15$ & $15.87 \pm 5.02$ & $\mathrm{P}<0.61$ \\
\hline $\mathrm{HDL}-\mathrm{C}(\mathrm{mmol} / \mathrm{L})$ & $38.10 \pm 2.51$ & $40.80 \pm 4.49$ & $\mathrm{P}<0.11$ \\
\hline $\mathrm{LDL}-\mathrm{C}(\mathrm{mmol} / \mathrm{L})$ & $74.70 \pm 12.15$ & $94 \pm 11.4$ & $\mathrm{P}<0.002$ \\
\hline Apo A-I $(\mathrm{mg} / \mathrm{dL})$ & $158.23 \pm 8.53$ & $159.59 \pm 8.37$ & $\mathrm{P}<0.73$ \\
\hline Lymphocyte $(\mathrm{n} \times 1000 / \mathrm{l}(\dot{ }$ & $2.70 \pm 0.84$ & $2.33 \pm 0.49$ & $\mathrm{P}<0.75$ \\
\hline ABCA1mRNA-lymphocyte(RU) & $76.16 \pm 6.34$ & $77.25 \pm 3.43$ & $\mathrm{P}<0.77$ \\
\hline
\end{tabular}

RU-relative units. 
ABCA1 and reverse cholesterol transport: $A B C A 1$ gene expressions in lymphocytes and plasma lipoprotein (HDL-C, LDL-C) were examined in subjects. Despite a reduction in lymphocyte count in both groups $(P<0.05)$, the ABCA1 gene expression in lymphocyte was significantly $(P<0.001, t=9.95)$ higher in the experimental group when compared with the control group (figures 1 and 2).

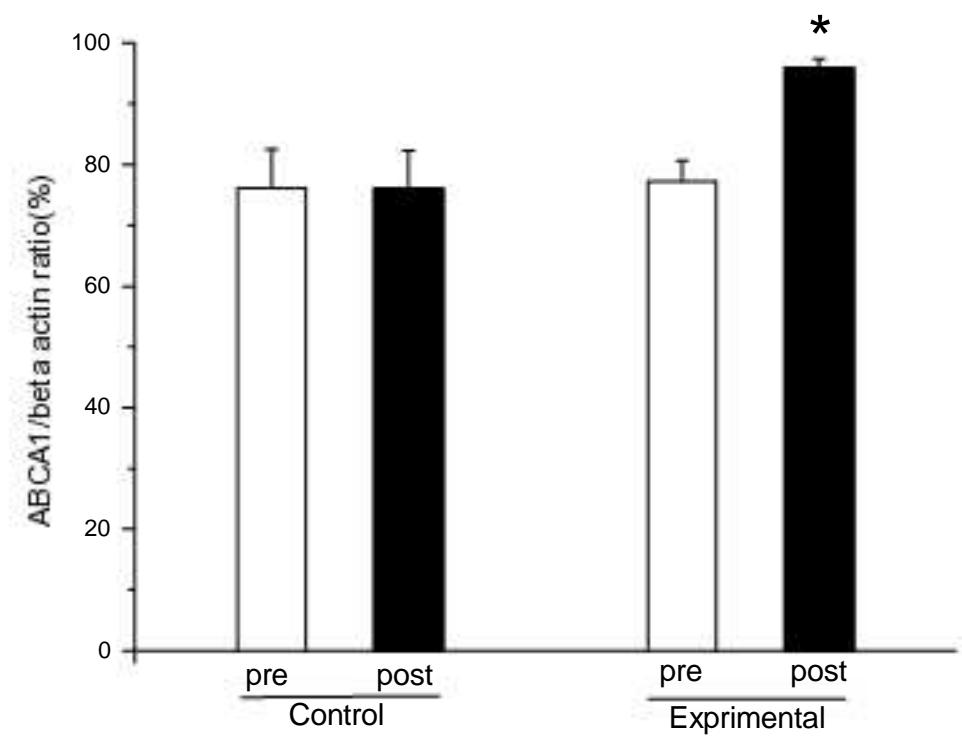

Figure1. Semi-quantitative RT-PCT of lymphocyte ABCA1 mRNA expression in two groups, prior and after research program (mean $\pm S D)$

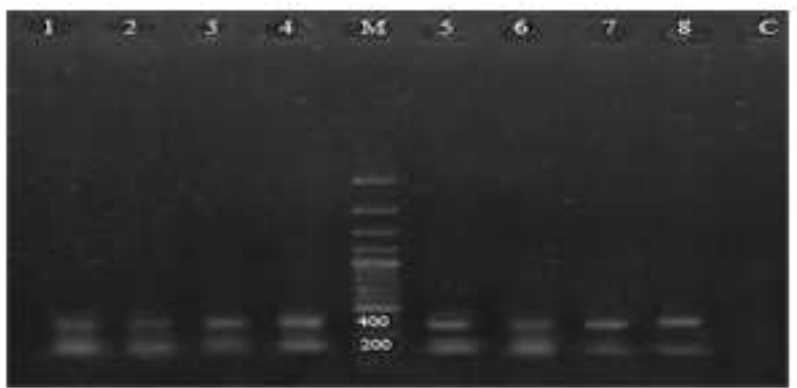

Control

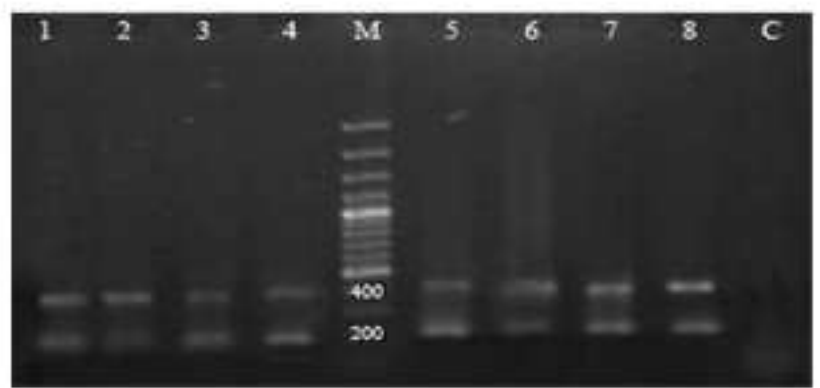

Experimental

Figure 2. Semi-quantitative RT-PCT of peripheral blood lymphocytes ABCA1 mRNA expression in control and experimental groups

Plasma HDL-C and Apo A-I concentrations were higher in the experimental group following the 8 weeks of wrestling training $(P<0.001, t=4.97$ and $P<0.001, t=2.67$ respectively). There was also a significant decrease in plasma LDL-C concentration in the experimental group compared to control group $(P<0.001, t=4.35)$. (Figure 3 ) 

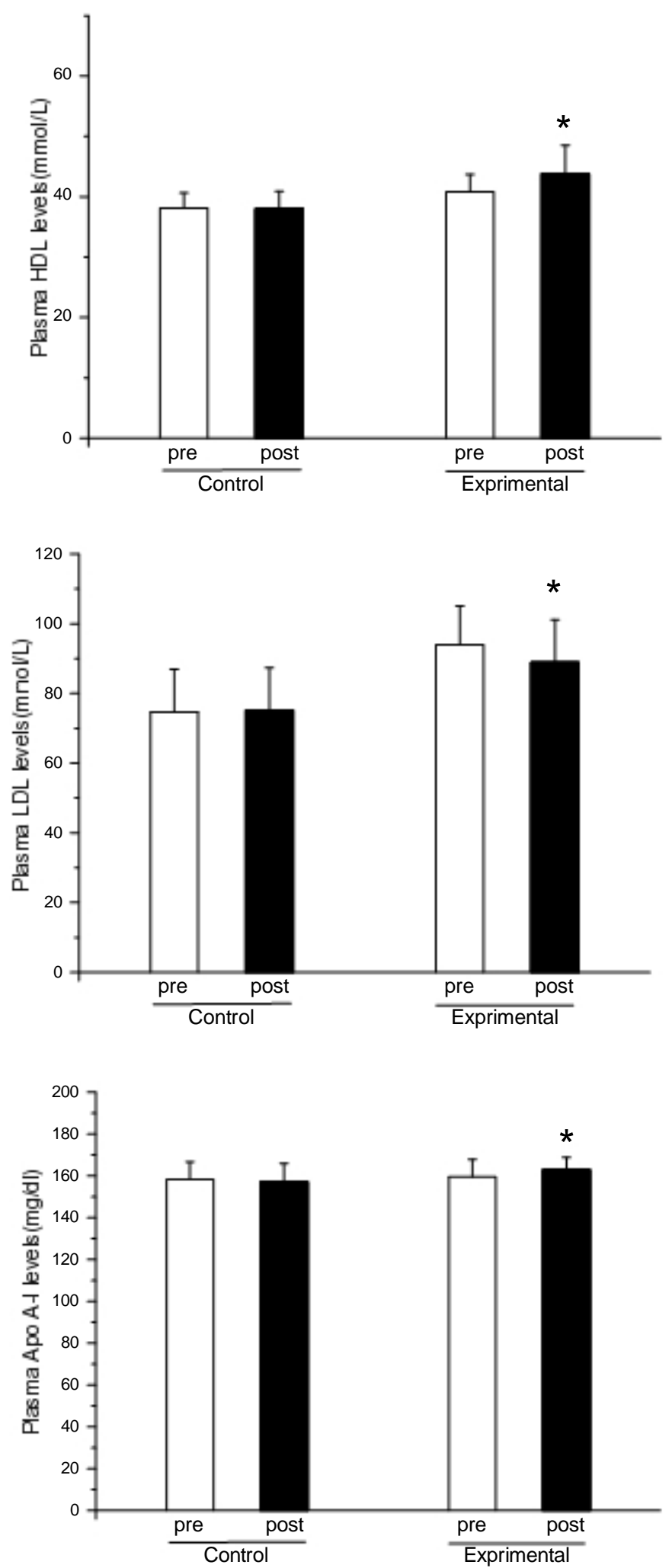

Fig. 3. Plasma HDL-C, LDL-C and apolipoprotein A-I concentrations after 8 weeks of research program in control and experimental group Data expressed as mean \pm SD. 


\section{CONCLUSIONS}

A gene expression in white blood cells in response to exercise has been shown by previous studies $[23,24,25,26]$. The effect of exercise programs (acute and chronic) on reverse cholesterol transport (RCT) and its key elements except ABCA1 has been studied by several investigators, but to our knowledge this is only the third human study to demonstrate that $A B C A 1$ is expressed by peripheral blood lymphocytes due to exercise $[20,27]$. The main finding of present study was that eight weeks of wrestling exercise with $85-90 \%$ of HR max, increased the ABCA1 expression on lymphocytes in well trained wrestlers. Plasma HDL-C and apo A-I levels increased following eight weeks of wrestling and wrestling based training. Furthermore plasma LDL levels decreased significantly following the protocol.

Our findings on $A B C A 1$ expression are partly similar to Ghanbari-niaki et al findings. When they calculated the expression of ABCA1 mRNA in peripheral blood lymphocyte found significant increase in a short time after exercise in all given exercise intensities $(40 \%, 60 \%$, and $80 \%$ of one repetition maximum) and was more pronounced in $60 \%$ group. In addition plasma HDL concentrations showed a moderate change immediately due to exercise. The result also shows that a higher lymphocyte ABCA1 expression was not accompanied with a significant change in plasma HDL [27].

In Hoang et al study ABCA1 expression was measured in human skeletal muscle biopsies and leukocytes and physical activity (habitual exercise) were assessed using International Physical Activity Questionnaire (IPAQ). The main findings of Hoang et al were that leukocyte ABCA1 expression relates positively with frequency of exercise and muscle ABCA1 expression relates positively with alcohol consumption [20]. Khabazian et al reported that six week of endurance training increased Liver and intestine ABCA1 mRNA expression significantly higher in trained rats compared to control rats $[9,18]$. In the present study, we investigate lymphocyte ABCA1 gene expression in human and use specific eight weeks training protocol that may be more accurate than questionnaire or acute exercise.

Jurimae et al studied the effect of a circuit resistance protocol ( 3 circuits, 10 exercise using a work-to-rest ratio of $30 \mathrm{~s}: 30 \mathrm{~s}$ at $70 \%$ of $1 \mathrm{RM}$ ) on HDL-C and other lipid and lipoprotein profiles. They reported results showed that LDL-C, and HDL-C concentrations remained unchanged immediately after exercise, but an elevation in plasma HDL-C observed after $1 \mathrm{~h}$ of recovery period [28]. There is little doubt that ABCA1 interacts directly with ApoA-I. However, this does not exclude that ABCA1 might also efflux lipids onto ApoA-I at the cell surface. Concerning the substrate specificity, phospholipids rather than cholesterol seem to be transported by ABCA1 [7].

In Olchawa et al study, 25 endurance-trained male athletes (VO2max $=53.4 \pm 1.2 \mathrm{~mL} / \mathrm{min}$ per $\mathrm{kg}$ ) were compared with 33 males enjoying an active lifestyle $(\mathrm{VO} 2 \mathrm{max}=38.8 \pm 1.0 \mathrm{~mL} / \mathrm{min}$ per $\mathrm{kg})$. Plasma concentrations of $\mathrm{HDL}-\mathrm{C}(1.4 \pm 0.1$ versus $1.7 \pm 0.1 \mathrm{mmol} / \mathrm{L}, \mathrm{p}<0.001)$ and $A p o A-I \quad(128 \pm 3$ versus $145 \pm 2 \mathrm{mg} / \mathrm{dL} \mathrm{p}<0.001)$ were higher in athletes compared with active subjects [29]. Both systemic and selective hepatic over expression of ABCA1 in mice results in an increase of HDL-C plasma levels. Vice versa, apoA-I and HDL plasma levels are dramatically reduced in mice with a liver-specific deletion of ABCA1 [17,30]. Hence, hepatic ABCA1 expression is a ratelimiting factor for plasma HDL production [31]. Although ABCA1 in macrophages has little influence on plasma HDL levels, it is a crucial factor in the prevention of excessive cholesterol accumulation in macrophages of the arterial wall and their transformation in foam cells, independently of plasma HDL levels. Regulation of ABCA1 expression in leukocytes may partially reflect that in macrophages [20].

\section{PRACTICAL IMPLICATIONS/ADVICE FOR ATHLETES AND COACHES}

Anaerobic exercises such as wrestling can increase plasma HDL and Apo-I, decrease LDL concentrations and also enhance ABCA1 gene expression on lymphocytes so that they are effective factors in the prevention of cardiovascular disease.

\section{REFERENCES}

1. Gordon D.J., Rifkind B.M. (1989). High-density lipoprotein-The clinical implications of recent studies. N. Engl. J. Med, 321: 1311-1316.

2. Brousseau M.E., Hoeg J.M. (1999). Transgenic rabbits as models for atherosclerosis research. J. Lipid Res, 40:365-375.

3. Morgan J., Carey C., Lincoff A.,et al. (2004). High-density lipoprotein subfractions and risk of coronary aretery disease. Curr Atheroscler Rep, 6:359-365.

4. Salonen J.T., Salonen R., Seppanen K., et al. (1991). HDL, HDL2, and HDL3 subfractions and the risk of acute myocardial infarction. A prospective population study in eastern Finnish men. Circulation, 84:129-139 
5. Yancey P.G., Bortnick A.E., Kellner-Weibel G., et al. (2003). Importance of different pathways of cellular cholesterol efflux. Arterioscler Thromb Vasc Biol, 23:712-719.

6. Barter P.J., (2002). Hugh Sinclair Lecture: the regulation and remodeling of HDL by plasma factors. Atheroscler Suppl, 3:39-47

7. Cavelier C., Lorenzi I., Rohrer L., et al. (2006). Lipid efflux by the ATP-binding cassette transporters ABCA1 and ABCG1. Biochim Biophys Acta, 1761:655-666

8. Zannis V.I., Chroni A., Krieger M., et al (2006). Role of ApoA-I, ABCA1, LCAT, and SR-BI in the biogenesis of HDL. J Mol Med, 84:276- 294.

9. Khabazian B.M., Ghanbari-Niaki, A., Safarzadeh-Golpordesari A.R., et al. (2009). Endurance training enhances ABCA1 expression in rat small intestine. Eur J Appl Physiol, 107:351-358

10. Langmann T., Klucken J., Reil M., et al. (1999). Molecular cloning of the human ATP-binding cassette transporter 1 (hABC1): evidence for sterol-dependent regulation in macrophages, Biochem. Biophys Res Commun, 257:29-33.

11. Kielar D., Dietmaier W., Langmann T., et al (2001). Rapid quantification of human ABCA1 mRNA in various cell types and tissues by real-time reverse transcription-PCR. Clin Chem, 47:2089-97.

12. Basso F., Freeman L., Knapper C.L., et al. (2003). Role of the hepatic ABCA1 transporter in modulating intrahepatic cholesterol andplasma HDL cholesterol concentrations. J Lipid Res, 44:296-302.

13. Basso F., Freeman L., Knapper C.L., et al. (2004). ABCA1-dependent lipid efflux to apolipoprotein A-I mediates HDL particle formation and decreases VLDL secretion from murine hepatocytes. J Lipid Res, 45:1122-1132.

14. Timmins J.M., Lee L.Y., Boudyguina E., et al. (2005). Targeted inactivation of hepatic Abca1 causes profound hypoalphalipoproteinemia and kidney hypercatabolism of apoA-I. J. Clin. Invest, 115:1333-1342.

15. Singaraja R.R., Van-Eck M., Bissada N., et al. (2006). Both Hepatic and Extrahepatic ABCA1 Have Discrete and Essential Functions in the Maintenance of Plasma High- Density Lipoprotein Cholesterol Levels In Vivo. Circulation, 114:1301-1309.

16. Singaraja R.R., James E.R., Crim J., et al. (2005). Alternate transcripts expressed in response to diet reflect tissue-specific regulation of ABCA1. J Lipid Res, 46(10):2061-2071.

17. Singaraja R.R., Fievet C., Castro G., et al.(2002). Increased ABCA1 activity protects against atherosclerosis. J Clin Invest, 110(1):35-42.

18. Ghanbari-Niaki A., Khabazian B.M., Hossaini-Kakhak S.A., et al. (2007). Treadmill exercise enhances ABCA1 expression in rat liver. Biochem Biophys Res Commun, 361:841-846.

19. Oram J.F., Lawn R.M., et al. (2001). ABCA1: The gatekeeper for eliminating excess tissue cholesterol. J Lipid Res, 42:1173-9.

20. Hoang A., Tefft C., Duffy S.J., et al. (2008). ABCA1 expression in humans is associated with physical activityand alcohol consumption. Atherosclerosis, 197(1):197-203

21. Hovingh G.K., Wijland M.J.A., Brownlie A., et al. (2003). The role of the ABCA1 transporter and cholesterol efflux in familial hypoalphalipoproteinemia. J Lipid Res, 44:1251-5.

22. Dale R., Wagner M.E., (1996). Body composision assessment and minimal weight recommendation for high school wrestlers. Journal of athletic training, 31(3): 262-269.

23. Fehrenbach E., Niess A.M., Schlotz E., et al. (2000). Transcriptional and translational regulation of heat shock proteins in leukocytes of endurance runners. J Appl Physiol, 89(2):704-10.

24. Connolly P.H., Caiozzo V.J., Zaldivar F., et al. (2004). Effects of exercise on gene expression in human peripheral blood mononuclear cells. J Appl Physiol, 97(4):1461-1469.

25. Zieker D., Fehrenbach E., Dietzsch J., et al. (2005). cDNA microarray analysis reveals novel candidate genes expressed in human peripheral blood following exhaustive exercise. Physiol Genomics, 23:287-294.

26. Buttner P., Mosig S., Lechtermann A., et al. (2007). Exercise affects the gene expression profiles of human white blood cells. J Appl Physiol, 102 (1): 26-36.

27. Ghanbari-Niaki A., Saghebjoo M., Hedayati M., (2010). A single session of circuit resistance exercise effects on human peripheral blood lymphocyte ABCA1 expression and plasma HDL-C level, Regulatory Peptides. Article in press.

28. Jurimae T., Karelson K., Smirnova T., et al. (1990). The effect of a single-circuit weight-training session on the blood biochemistry of untrained university students. Eur J Appl Physiol Occup Physiol. 61:344-348.

29. Olchawa B., Kingwell B.A., Hoang A., et al. (2004). Physical Fitness and Reverse Cholesterol Transport. Arterioscler Thromb Vasc Biol, 24:1087-91.

30. Haghpassand M., Bourassa P.A., Francone O.L., et al. (2001). Aiello, Monocyte Macrophage expression of ABCA1 has minimal contribution to plasma HDL levels. J Clin Invest, 108: 1315-1320.

31. Aiello R.J., Brees D., Bourassa P.A., et al. (2002). Increased atherosclerosis in hyperlipidemic mice with inactivation of ABCA1 in macrophages. Arterioscler Thromb Vasc Biol, 22:630-637. 